\title{
Modeling Self Medication Risk Factors (A Case Study of Kiambu County, Kenya)
}

\author{
Thomas Mageto, Allan Zablon \\ Department of Statistics and Actuarial Science, Jomo Kenyatta University of Agriculture and Technology, Nairobi, Kenya
}

Email address:

tttmageto@gmail.com (T. Mageto)

\section{To cite this article:}

Thomas Mageto, Allan Zablon. Modeling Self Medication Risk Factors (A Case Study of Kiambu County, Kenya). American Journal of Theoretical and Applied Statistics. Vol. 7, No. 2, 2018, pp. 58-66. doi: 10.11648/j.ajtas.20180702.12

Received: January 15, 2018; Accepted: January 29, 2018; Published: February 27, 2018

\begin{abstract}
In this paper self-medication risk factors are investigated and multivariate model proposed. A random sample of four major hospitals was selected, one from each sub-county and sample of 728 patients selected from selected hospitals using stratified random sampling. The data was collected using semi structured questionnaires and analyzed in $\mathrm{R}$ program after cleaning for non-response. Preliminary analysis was carried to check for statistical significance of the risk factors of age, gender, income, marital, education, employment and insurance status. All proposed risk factors were statistically significant except employment factor when using chi-square test for each of discrete variables while both age and income continuous variables were significant at $\alpha=0.05$ level of significance when fitting simple logistic regression model. The initial multivariate logistic regression model was fitted and variables of marital and insurance status of persons were statistically insignificant and therefore improved model was fitted less marital and insurance factors. The overall significance of the model was determined using Hosmer and Lemeshow goodness-of-fit test and the model recorded p-value of 0.7751 that indicates that there is no significant difference between observed and predicted probability, therefore the model would be used to predict chance of selfmedication in the presence of significant risk factors. In conclusion therefore there is need to initiate legislation on policies that will guide self-medication that include provision of necessary knowledge and regulating the practice to avoid over dose, wrong prescriptions and emergence of human pathogen resistance microorganisms or serious consequences like resistance to medication in future guided by the prevalence results obtained from proposed model.
\end{abstract}

Keywords: Medication, Prevalence, Multivariate Logistic Regression, Risk Factors, Chi-Square and Goodness-of-Fit

\section{Introduction}

\subsection{Background of Study}

The health of an individual is defined as state of complete physical, mental, and social well-being and not merely the absence of diseases or infirmity. As with all human actions, the decisions regarding health behavior are influenced in part by external stimuli, for instance, pharmacist advising patient and also by internal states such as those thoughts, feelings and beliefs. Patients understand their illness within their own conceptual framework and process information and make decision on whether they need to seek treatment or not that range from visiting public hospitals, private clinics or chemists. An emerging form of treatment in Kiambu County is self-medication where persons treat common health problems without prior medical consultation regarding indication, dosage and duration of treatment [1]. The taking of drugs, herbs or home remedies on one's initiative or advice of another person without consulting a doctor may lead to shift in the pattern of disease towards chronic ones (from $30 \%$ to $80 \%$ in 40 years) with shift from cure to care and thus becomes great concern to many emerging studies worldwide [2]. The inadequacies of health care system with misdistribution of drugs, rising cost and the issue of curative stance of drugs are some of other reasons for the practice. Medications may be approved as being safe for selfmedication by the regulatory authority and such medicines are normally used for prevention or treatment of minor ailments or symptoms which do not justify medical consultation. In some chronic or recurring illnesses, after initial diagnosis and prescription, self-medication is possible 
with the doctor retaining an advisory role. In several studies it has been found that inappropriate self-medication results in wastage of resources, increases resistance of pathogens and generally entails serious health hazards such as greater probability inappropriate treatment, pathogen resistance, increased morbidity, adverse drug reactions, prolonged suffering and drug dependence [3]. On the other hand, if selfmedication is done appropriately, it can readily relieve acute medical problems, save time spent in waiting to see a doctor, may be economical and can even save lives in serious conditions. It is now accepted that self-care in the form of responsible self-medication can be beneficial for patients, healthcare providers, pharmaceutical industry and governments. Modern patients have taken great role in maintenance of their own health and we wish therefore to study factors influencing self-medication and potential risks.

\subsection{Problem Statement}

Self-medication with prescription medicines is known to occur in developing economies since prescription medicines are freely sold over the counter (OTC) because regulations have not been fully implemented. The practice may result in health hazards resulting from failure to recognize warning symptoms of disease, missed diagnosis, incorrect therapy, failure to follow precautions, use of an inadequate or excessive dose and failure to seek subsequent medical advice [4]. This study will seek to investigate risk factors that influence self-medication and propose recommendations that will influence limitation of the practice of using medicinal products without advice from qualified medical personnel.

\subsection{Objectives}

\section{General objective}

To investigate social economic risk factors associated with self-medication and propose estimating prevalence model.

Specific objectives

(i) To assess and propose self-medication risk factors associated with self-medication

(ii) To fit multivariate logistic regression model for predicting self-medication prevalence

(iii) To test suitability of predictive model and apply it in predicting prevalence.

\subsection{Hypothesis}

In order to achieve the objectives the following hypothesis is considered;

$\mathrm{H}_{0}$ : There is no relationship between self-medication and social economic risk factors

$\mathrm{H}_{\mathrm{a}}$ : There is a relationship between self-medication and social economic risk factors

\subsection{Justification}

The health of persons is of great concern to the nation and policy makers have always made resources available for medical care in counties. However, facilities, personnel and drugs have not been adequate to serve the high increasing population. The scarcity of resources has led to patients involving themselves in self-medication as a measure of selfcare. The practice comes with spectrum of benefits as well as side effects that would lead to health complications to drug induced diseases and wasteful public expenditure. In order to promote responsible self-medication it is important that an investigation of risk factors contributing to the practice is considered. The research study will come up with statistical model that may be used to explain how the risk factors or combination of these risk factors describe current prevalence levels of self-medication in area of study.

\section{Literature Review}

Self-medication is a form of self-care that is of great interest among researchers and health policy makers owing to its advantages and disadvantages associated with its practice in general population. Self-care is not new but rather an old and widely used form of care practiced in society that affects health of individuals. The contemporary self-care is a response of developments and attitudes regarding the role of individuals that occurred over the past hundred years [5]. The practice of self-medication has been defined as substitute, supplementary or additive to professional care or discrete component in the health care delivery system. As there are many authors and professions concerned with health and selfmedication, there are different definitions to self-medication. However, all definitions agree on the main concepts of selfmedication as diagnosis, self-care, self-treatment and/or patient participation in professional care. Self-medication is active and is participatory rather than passive receiving of care or directives given by professionals. Self-medication is a behavioral response of individuals to promote or restore their health and encouragement of self-care is seen as giving patients every opportunity to take responsibility and build confidence in their ability to manage their own health. The practice has advantages that include, saving scarce medical resources, lowering costs of community funded health care programs, reducing absenteeism from work, reducing pressure on medical services and increase of availability of health care populations in rural areas [6].

Patient empowerment is viewed as positive step in development of the relationship between patient and healthcare provider and considered an important health policy concept. However, it is also recognized that selfmedication must be accompanied by appropriate health information. Despite the growing research interest in selfmedication, paucity of information about the rational use of such practice and its major determinants especially in developing countries [7]. Studies on factors influencing the pattern of self-medication practice should be of interest to public health practitioners due to its possible deleterious effects especially in societies with high levels of illiteracy, for instance, Kenya has literacy in the $18-65$ age bracket at $72.2 \%$, up from a mere $25 \% 30$ years ago. This study will be out to provide practical insights into the insight of selfmedication in urban and rural community, which represents 
social economically and educationally deprived population. Based on past studies prevalence are recorded as South Africa (14\%), UK (9\%), Australia (11\%), Germany (11\%), US (13\%), Sweden (9\%), Italy (8\%), Spain (9\%), Switzerland(8\%), Mexico (8\%), and therefore there are significant number that opt out of going to hospitals for diagnosis and prescription, and prefer alternative selfmedication instead [3].

There are spectrums of reasons why people choose to treat themselves that includes; first, cost of self-medication, that is, majority of people would rather buy their own medicine from over the counters and treat themselves rather than go to hospitals because doctors charge consultation fee that many people may not afford. Secondly, recurring symptoms of known ailment, that is, sometimes people suffer from illnesses that they have experienced before. In such a case, they decide not to go to hospital since they already know how to treat the illness and the drugs needed. Thirdly, efficiency in self-care in current technological stance, many people rather check their symptoms online and self-diagnose themselves and get medication from stores without going for prescription or diagnosis, and this is quick and saves costs to patients. Fourthly, lack of faith in doctors, that is, number of many people does not have any faith in medical personnel, may be due to previous cases of misdiagnosis. This makes them believe in their own modes of treatment, selfmedication being their first option, last but not least, literacy levels, with high literacy level, many people have opted for self-medication since most medications come with some form of instruction on how to take them. Surge in number of chemists and pharmacies has led to medication has become as easy to get as being on the doorstep. Many private pharmacies and clinics have opened up in residential areas where one can easily purchase medicines and freely selfmedicate [8].

There exists similarities in ailments that are treatable with self-medication across European countries; however, there are significant differences in the share that self-medication products have on the total pharmaceutical market. These range from $26.1 \%$ in Switzerland system which encourages self-medication down to $7.8 \%$ of the total market in Sweden. In the large pharmaceutical market UK (20.7\%) and Germany $(17.7 \%)$ of the total pharmaceutical market is accounted for by self-medication products [5]. The use of Over the Counter medicines prevail in many countries, for instance, Canada has $44 \%$ of patients who practice self-care while in Hong Kong, $65 \%$ of respondents used OTC medications. A study in US showed $96 \%$ of patients used OTC. Studies observed that $59 \%$ collected prescription medicine $40 \%$ had purchased over the counter medicine from pharmacy, $12 \%$ had sought advice, $76 \%$ female had obtained medicine or advice but only $63 \%$ of men had obtained medicine or sought for advice. In other countries OTC recorded South Africa (37\%), Us (33\%), Germany (28\%), Mexico $21 \%$ and Italy (20\%) and the use of complimentary medicines is due to emergence of new set of beliefs about nature, science, rejection, responsibility and consumerism
[9]. The Previous worldwide study record that the proportion of un-prescribed to prescribed drugs is 4:7 with analgesics, antipyretics and expectorant as the most commonly requested ones. A study done in the past decade observed that selfmedication in developing countries where universal access has not been achieved is a common preferred mode of treatment even though it may lead to delay care seeking that may result in paradoxical economic loss. The practice may also expose patients into use of drugs that may be prevented had patient sought advice from qualified medical practitioner [10].

All over the world people suffer from common diseases like colds, headaches, digestive problems and muscle aches in almost the same percentages of which $50 \%$ the condition is left to run its course or resort to using home remedy, $25 \%$ of patients seek medical advice or resort to treatment using previous prescription for same condition while the rest seek the medical practitioners advice [11]. The high percentage of patients not seeking the advice of trained medical personnel has a high potential of developing drug-resistant microorganisms that will lead to treatment failure. Irrational use of other drugs may result to gastrointestinal complications, effects on kidney, hepatic injury and risk of cardiovascular events [12]. In Nigeria study on $91.4 \%$ respondents were found to practice self-medication while $8.7 \%$ were not, the preference was generally high among middle age groups while lower and higher age groups recorded lower prevalence of self-medication. Females recorded higher prevalence than male and there was significant association with age, gender and education level at $\alpha=0.01$ level of significance [13]. The literature review collected has focused mainly on prevalence and less on models that may be used to consider individual risk factors or more than one risk factor in model that can give overall assessment of the prevalence. In this study focus is on proposing single multivariate logistic regression model that will give overall assessment of the risk factors and suggest recommendations based on results obtained.

\section{Methodology}

\subsection{Sampling Procedure and Sample Size}

The study was conducted is Kiambu County on general outpatient in four major sub-county hospitals. Ethical clearance was obtained from Ethical committees prior to collecting data for the study. Information was sought from each of the respondents and consent obtained before interviewing or administering semi structured questionnaire. The sample was selected using stratified sampling such that each sample from each sub-county hospital was selected based on population size such that $\mathrm{n}_{\mathrm{i}}=\frac{\mathrm{N}_{\mathrm{i}} \mathrm{n}}{\mathrm{N}}$, and from each stratum the sample was selected using simple random sample without replacement. The total sample size was determined using formula [14] given as follows: 


$$
\begin{gathered}
\mathrm{n}=\frac{\chi_{1-\alpha}{ }^{2} \mathrm{NP}(1-\mathrm{P})}{\mathrm{e}^{2}(\mathrm{~N}-1)+\chi_{1-\alpha}{ }^{2} \mathrm{P}(1-\mathrm{P})} \\
=\frac{3.841^{2}(1435)(0.5)(1-0.5)}{0.05^{2}(1435-1)+3.841^{2}(0.5)(1-0.5)} \\
=728
\end{gathered}
$$

Where $\mathrm{n}$ is the sample size, $\chi_{(1-\alpha)}$ is the chi-square distribution value at $\alpha$ level of significance, e is the level of precision and $\mathrm{P}$ is proportion of the attribute that is present in the population under study.

The sample size from each sub-county hospital was obtained as a proportion of the number of patients visiting sub-county hospitals, that is, $\mathrm{n}_{\mathrm{i}}=\frac{\mathrm{N}_{\mathrm{i}}}{\mathrm{N}}$, such that $\mathrm{N}_{1}=248$, $\mathrm{N}_{2}=528, \mathrm{~N}_{3}=302$ and $\mathrm{N}_{4}=357$, that is, we selected sample of sizes $\mathrm{n}_{1}=126, \mathrm{n}_{2}=268, \mathrm{n}_{3}=153$ and $\mathrm{n}_{4}=181$. In each stratum we selected sample using simple random sampling procedure such that each sample had an equal probability of being selected.

\subsection{Proposed Model and Inclusion Population}

The study population was patients visiting major hospitals in four sub-counties. The data available on self-medication include and not limited to the following: whether or not a person practice self-medication, age, income, gender, marital, education level, employment status, membership of insurance fund, type of medication before current type, frequency of self-medication, conditions or type of illness, nature of drugs, source of advice, reasons for practice, source of dose information and cure status. A multivariate logistic regression model was fitted in which proposed risk factors of self medication were considered. The model was given due consideration as a better model to fit data because response variable (whether a person practice self-medication or not) is dichotomous and predictor variables are combination of continuous and categorical variables.

The first step in fitting multivariate logistic regression is to test whether there is an association between response variable and each of the predictors using chi-square test of independence, that is, test hypothesis;
$\mathrm{H}_{0}$ : self-medication and predictor variable are not associated

$\mathrm{H}_{\mathrm{a}}$ : self-medication and predictor variable are associated

The test statistic is given as $X^{2}=\sum_{i=1}^{n} \frac{\left(O_{i}-E_{i}\right)^{2}}{E_{i}}$ Where

$\mathrm{O}_{\mathrm{i}}$ the observed value and $\mathrm{E}_{\mathrm{i}}$ is the expected value

The null hypothesis is rejected if the p-value is less than 0.05 at $\alpha=0.05$ level of significance.

The statistically significant predictor variables are then considered when fitting the multivariate logistic regression model. The odds of outcome occurring or not is examined and using natural log of the odds of an outcome as the dependent variable, the relationships can be made linear and treated like multivariate linear regression. Consider response variable of binary $\mathrm{Y}$ and multiple predictor variables denoted by $\mathrm{X}_{1}, \mathrm{X}_{2} \ldots \mathrm{X}_{\mathrm{k}}$. If $\pi$ represents the probability, $\mathrm{P}(\mathrm{Y}=1)$ that is presence of outcome and $1-\pi$ to represent probability, $\mathrm{P}(\mathrm{Y}=0)$, multivariate logistic regression model can be written as:

$$
\pi=P\left(Y \mid X_{1}, X_{2}, \ldots, X_{k}\right)=\frac{e^{\beta_{0}+\beta_{1} X_{1}+\beta_{2} X_{2}+\ldots+\beta_{k} X_{k}}}{1+e^{\beta_{0}+\beta_{1} X_{1}+\beta_{2} X_{2}+\ldots+\beta_{k} X_{k}}}
$$

Where $\beta_{0}, \beta_{1} \ldots \beta_{\mathrm{k}}$ are the regression coefficients

In multivariate logistic regression, the outcome is the expected $\log$ of odds that the outcome is actually present such that, $\ln \left(\frac{\pi}{1-\pi}\right)=\beta_{0}+\beta_{1} X_{1}+\beta_{2} X_{2}+\ldots+\beta_{k} X_{k}$. The expression on the right hand side of equation is similar to multivariate regression model. The coefficients in multivariate logistic regression are said to be the change in expected log odds relative to unit change in $\mathrm{X}_{\mathrm{i}}$ when all other risk factor variables take reference level values. The antilog of estimated regression coefficient, $\mathrm{e}^{\beta_{\mathrm{i}}}$ gives these odds ratios.

\subsection{Description of Study Variables}

\begin{tabular}{|c|c|c|}
\hline Variable & Variable Description & Code and description \\
\hline Self-medication & Response variable & 0 - no-self-medication, 1 - self-medication \\
\hline Age & Age of adults 18 years and above & Continuous variable \\
\hline Gender & Gender of sampled person & 0 - male, 1 - female \\
\hline Income & Earning of patient & Continuous variable \\
\hline Marital & Marital status & 0 - married, 1 - widowed, 2 - separated, 3 - divorced, 4 -never married \\
\hline Education & Level of education & 0 - no-formal, 1 - primary, 2 - secondary, 3 - tertiary \\
\hline Employment & Occupation of person & 0 - unemployed, 1 - formal, 2 - self employed \\
\hline Insurance & Membership status of insurance & 0 - registered, 1 - unregistered \\
\hline Source & Source of medication before & 0 - public health, 1 - private, 2 -self-medication, 3 -magic remedies, 4 -traditional, 5 - other \\
\hline Use & Frequency of usage & 0 -none, 1 -once, 2 -twice, 3 -thrice, 4 -four times, 5 -five and more times \\
\hline Condition & Type of illness & $\begin{array}{l}0 \text { - malaria, } 1 \text {-General illness, } 2 \text {-RTI, } 3 \text {-STD, } 4 \text {-eye, } 5 \text {-infections, } 6 \text {-headaches, } 7 \text {-fever, } 8 \text { - } \\
\text { skin, } 9 \text { - other }\end{array}$ \\
\hline Drugs & Category of drugs & $\begin{array}{l}0 \text {-antimicrobial, } 1 \text {-analgesic, } 2 \text {-respiratory, } 3 \text {-General illness, } 4 \text {-vitamin, } 5 \text {-ORS, } 6 \text { - } \\
\text { descriptive, } 7 \text {-other }\end{array}$ \\
\hline Advice & Source advice information & 0 -no information, 1 -read, 2 -friends, 3 -traditional, \\
\hline
\end{tabular}

Analysis coding scheme of response and predictor variables is summarized in Table 1 .

Table 1. Coding scheme for study variables. 


\begin{tabular}{lll}
\hline Variable & Variable Description & Code and description \\
\hline & & 4 -chemist, 5 -medics \\
Reason & Reason for practice & 0 -emergency, 1 - prevention, 2-morbidity, 3-cost, \\
Dose & D-name, 5 -category, 6 - symptoms, 7 -other \\
Cure & Dosage information source & 0 -previous prescription, 1 -seller, 2 -friend, 3 -package \\
\hline
\end{tabular}

\section{Results and Discussion}

The descriptive analysis and inferential analysis on risk factors associated with self-medication together with overall model assessment are presented in this section.

\subsection{Descriptive Statistics}

The collected data was recorded in contingency table and selected charts of variables were constructed as shown in Figure 1 to Figure 3. In figure 1 we observe that persons of all age groups except in $26-34$ years are likely to self medicate while there are more female who self medicate than male.

In Figure 2 it is observed that there is higher number persons of higher income earners who self-medicate as compared to lower income earners while higher number of unmarried persons self medicate as compared to widowed, separated, divorced and married persons. In Figure 3 there is higher number of persons who self medicate in higher education level compared to lower education level, unemployed persons practice self-medication than employed while number for insured persons practice self-medication than uncovered medical insurance persons.

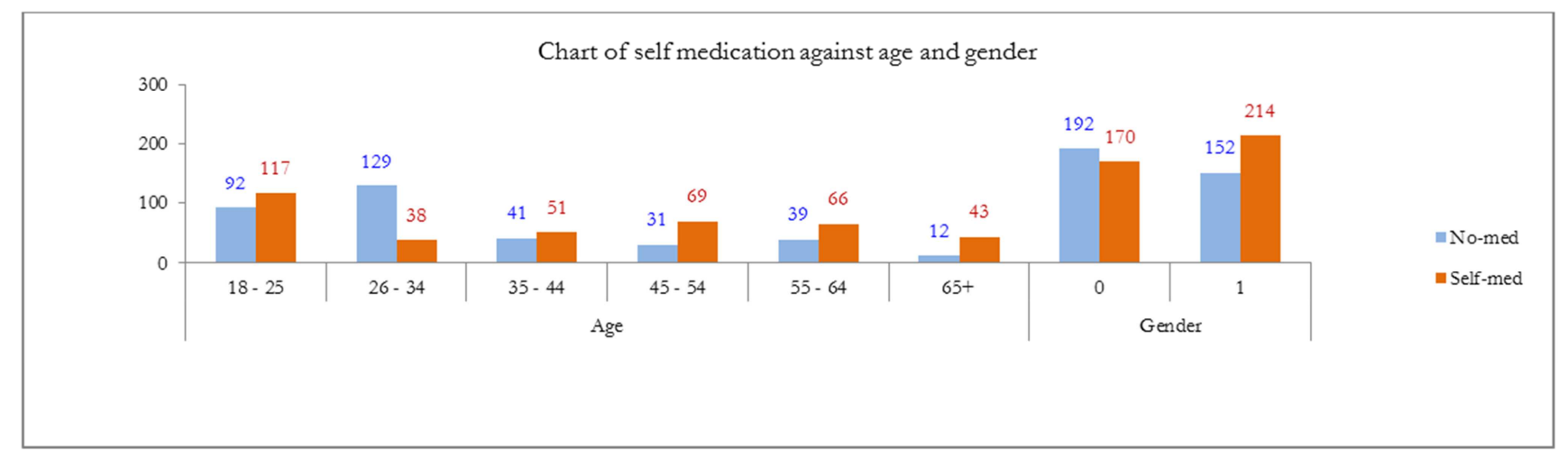

Figure 1. Chart of self medication against age and gender.

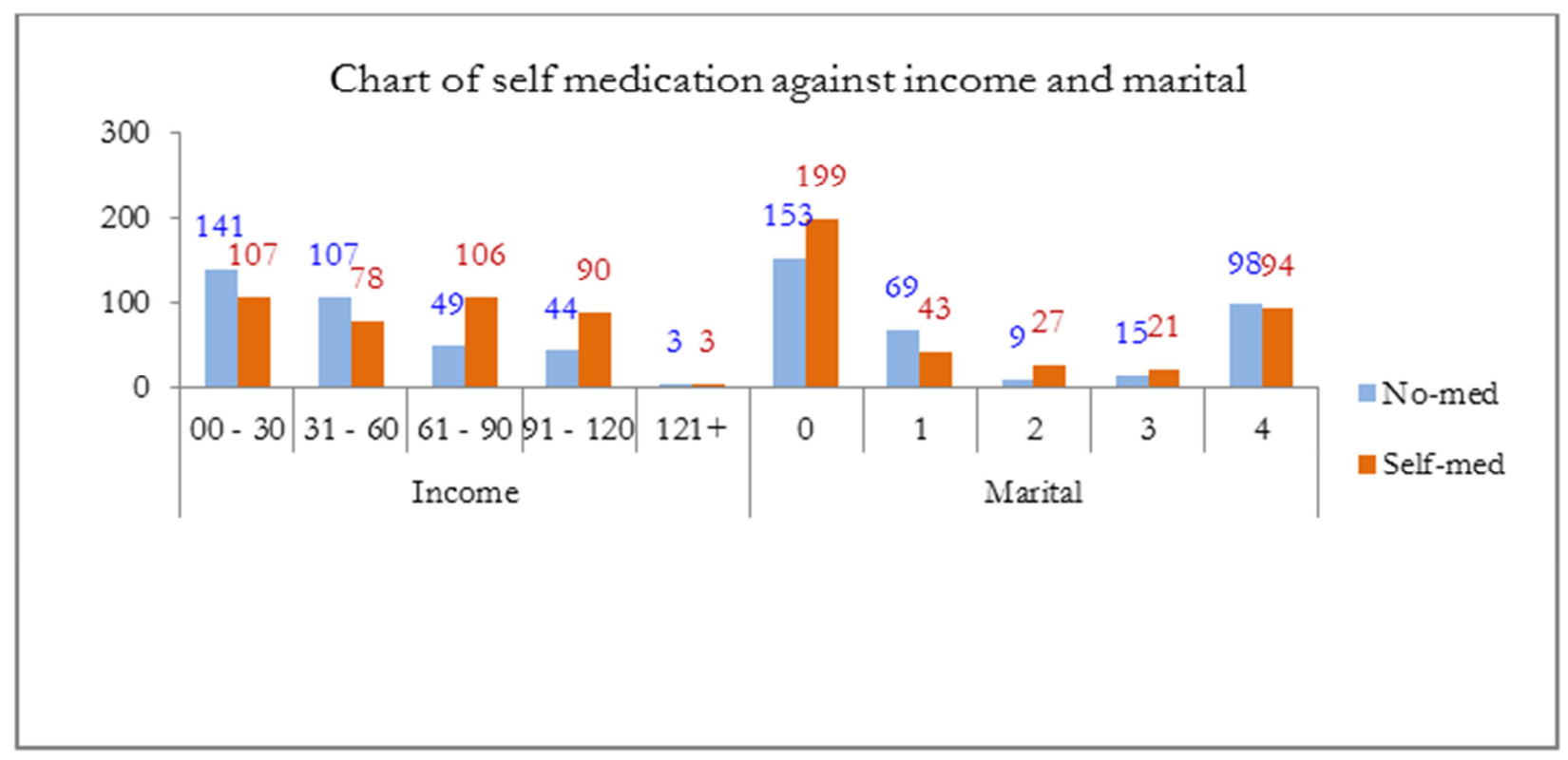

Figure 2. Chart of self medication against income and marital. 


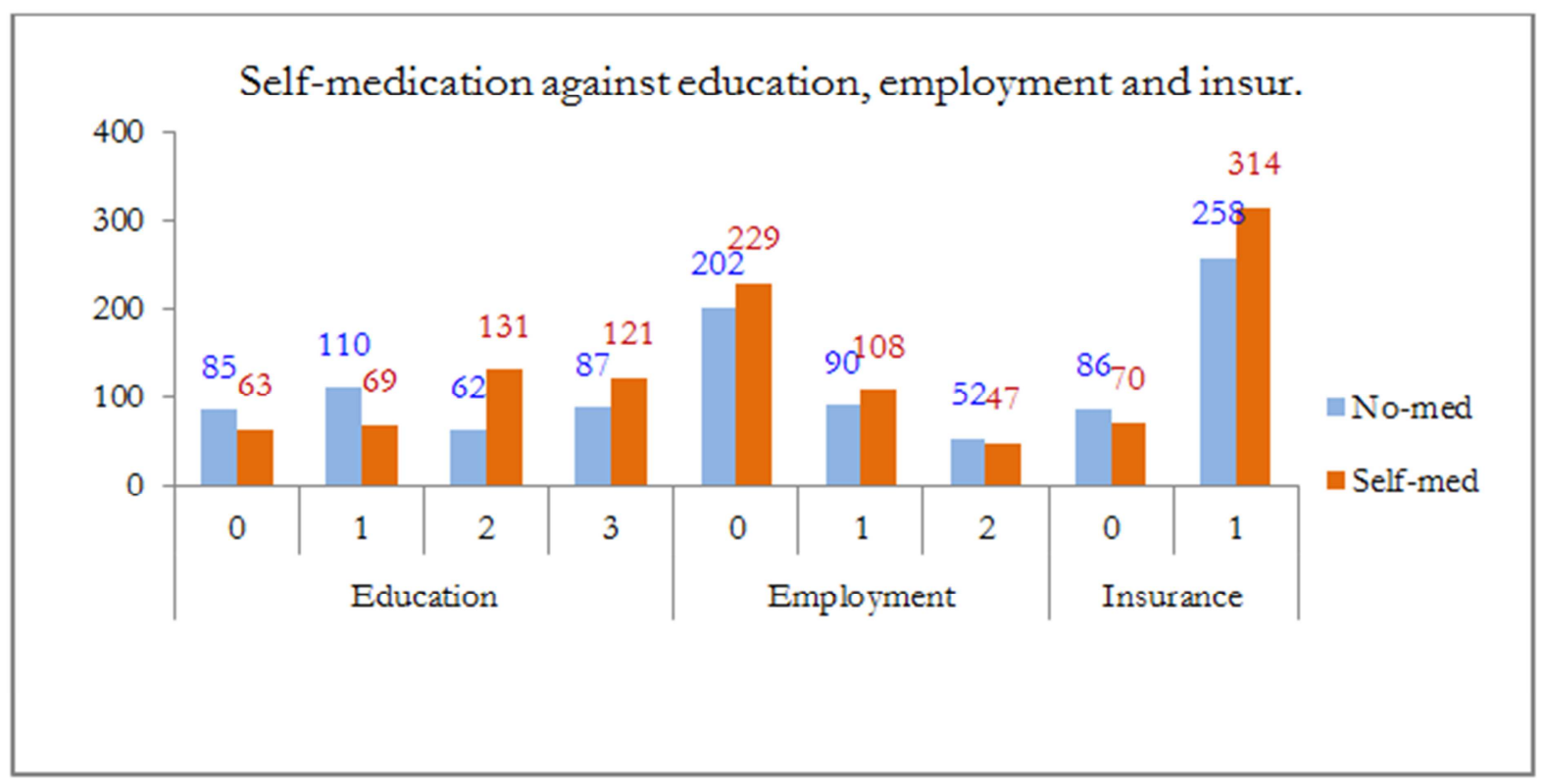

Figure 3. Chart of self medication against education, employment and insurance.

The preference of self-medication is given as;

Prevalence $=\frac{\text { Number of persons with condition }}{\text { Total population }} \times 100=\frac{380}{728} \times 100$

$=52 \%$ (that is, $52.2 \%$ of persons sampled practice self medication)

\subsection{Bivariate Analysis}

In bivariate analysis the association test of each of risk factor against self-medication using Chi-square test and results recorded in Table 2. However, in testing association of response variable with predictor variables of age and income, simple logistic regression model is fitted and then decision made whether the model is significant or not. The test is formally written in the form of hypothesis at $\alpha=0.05$ level of significance given as;

$\mathrm{H}_{0}$ : There is no association between medication and each of risk factors

$\mathrm{H}_{\mathrm{a}}$ : There is association between medication and each of risk factors

Table 2. Analysis p-values for Chi-square test.

\begin{tabular}{ll}
\hline Variable & p-value \\
\hline Age & 0.000005 \\
Income & 0.000003 \\
Gender & 0.002401 \\
Marital & 0.000501 \\
Education & 0.000000 \\
Employment & 0.499900 \\
Insurance & 0.032980 \\
\hline
\end{tabular}

The employment predictor variable has $\mathrm{p}$-value more than 0.05 , therefore the decision is fail to reject null hypothesis and conclude that there is no association between employment and self-medication, while p-values for predictor variables age, income, gender, marital, education and insurance have p-value less than 0.05 . The conclusion from this preliminary analysis is therefore that there is an association between response variable and each of the proposed risk factors except employment at $\alpha=0.05$ level of significance.

\subsection{Fitting Multivariate Logistic Regression Model}

A multivariate logistic regression model was considered and risk factors that were statistically significant were included in the model after the test of independence using chi-square analysis. The analysis results of generalized linear model are recorded as shown in Table 3.

Table 3. Multivariate logistic regression analysis.

\begin{tabular}{llll}
\hline Variable & Estimate & Std. Error & P-value \\
\hline Intercept & -2.1007 & 0.3133 & 0.000002 \\
Age $\left(\mathrm{X}_{1}\right)$ & 0.0205 & 0.0045 & 0.000004 \\
Income $\left(\mathrm{X}_{2}\right)$ & 0.0084 & 0.0019 & 0.000007 \\
Gender $\left(\mathrm{X}_{3}\right)$ & 0.5143 & 0.1572 & 0.001070 \\
Marital $\left(\mathrm{X}_{4}\right)$ & -0.0382 & 0.0462 & 0.407280 \\
Education $\left(\mathrm{X}_{5}\right)$ & 0.3037 & 0.0721 & 0.000025 \\
Insurance $\left(\mathrm{X}_{6}\right)$ & 0.3691 & 0.1913 & 0.053610 \\
\hline
\end{tabular}

The marital and insurance variables have p-values more than 0.05 then these two factors are therefore discarded from the proposed model and consider age, income, gender and education in the proposed multivariate logistic model. The 
analysis results for the multivariate model when considering significant variables are recorded in Table 4.

Table 4. Improved multivariate logistic regression model.

\begin{tabular}{|c|c|c|c|c|c|c|}
\hline \multirow{2}{*}{ Variable } & \multirow{2}{*}{ Estimate } & \multirow{2}{*}{ Std. Error } & \multirow{2}{*}{ P-value } & \multirow{2}{*}{$\begin{array}{l}\text { Odds } \\
\text { Ratio }\end{array}$} & \multicolumn{2}{|c|}{ Confidence Limits } \\
\hline & & & & & Lower & Upper \\
\hline Intercept & -1.874844 & 0.263273 & 0.000000 & 0.15338 & 0.09155 & 0.25696 \\
\hline Age $\left(X_{1}\right)$ & 0.020332 & 0.004436 & 0.000005 & 1.02054 & 1.01171 & 1.02945 \\
\hline Income $\left(\mathrm{X}_{2}\right)$ & 0.008325 & 0.001867 & 0.000008 & 1.00836 & 1.00468 & 1.01206 \\
\hline Gender $\left(\mathrm{X}_{3}\right)$ & 0.518607 & 0.156755 & 0.000938 & 1.67969 & 1.23537 & 2.28380 \\
\hline Education $\left(\mathrm{X}_{4}\right)$ & 0.313341 & 0.071657 & 0.000012 & 1.36799 & 1.18874 & 1.57426 \\
\hline
\end{tabular}

The final proposed multivariate logistic regression model includes variables age, income, gender and education given as;

$$
=\frac{\operatorname{P}\left(\mathrm{Y}=1 \mid \mathrm{X}_{1}, \mathrm{X}_{2}, ?, \mathrm{X}_{\mathrm{k}}\right)}{1+\exp \left(-1.8748+0.0203 \mathrm{X}_{1}+0.0083 \mathrm{X}_{2}+0.5186 \mathrm{X}_{3}+0.3133 \mathrm{X}_{4}\right)}
$$

The odd ratio for age when all the other variables are taken at reference for instance is 1.02054 , that is, if age of person increases by unit she/he is 1.02054 times likely to have self medication when all other variables are at reference levels. The odd ratio of income is 1.00836 , that is, if income of an individual increases by unit she/he is 1.00836 times likely to have self medication when all other variables are at reference level. The odd ratio for gender is 1.67969 , that is, a female is
1.67967 times likely to practice self medication when all other variables are at reference level. Similarly the odd ratio of education is 1.36799 , that is, a person who has primary level of education is 1.36799 times likely to have self medication than a person without formal education, while the one with tertiary education is 2.5600 times likely to have self medication than one without formal education. The odd ratio for intercept is 0.1534 , that is, male is 0.1534 times likely to have self medication when all the risk factors are taken at reference level.

The chart of probability self medication given age is given in Figure 4. In Figure 4 it is observed that as age of person increases, the probability of self-medication increases gently when all other variables are at reference level.

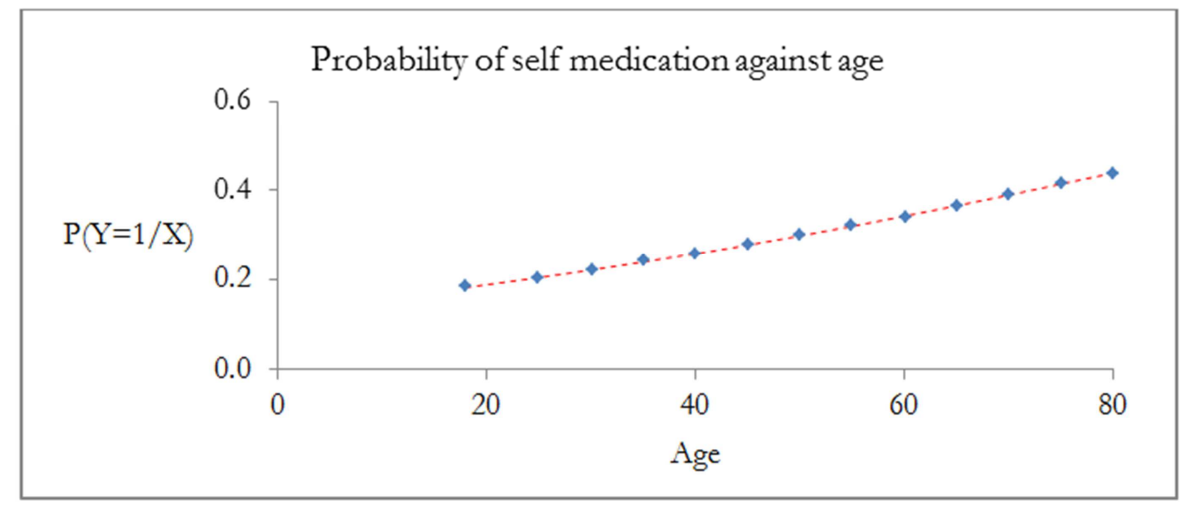

Figure 4. Probability of self medication against age.

In Figure 5 it is observed that, as income increases, probability of self medication increases as well when all other variables are taken at reference level.

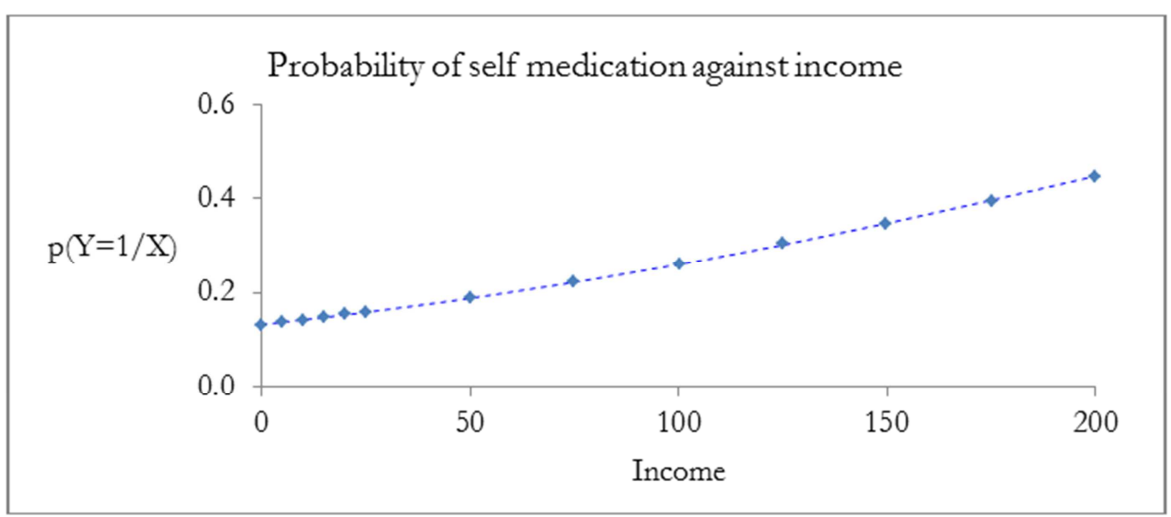

Figure 5. Probability of self medication against income. 


\subsection{Goodness-of-Fit Test}

The multivariate logistic model expected probabilities are compared with observed probabilities for self medication and results recorded. In a total of 344 persons who do not practice self-medication, $202(58.72 \%)$ are correctly predicted and $142(41.28 \%)$ are incorrectly predicted while among 384 persons who self-medicate, $264(68.75 \%)$ are correctly predicted and $120(31.25 \%)$ are incorrectly predicted. In overall $262(35.99 \%)$ are incorrectly predicted while 466 (64.01\%) are correctly predicted. The Hosmer and Lemeshow goodness-of-fit test is considered appropriate test and therefore used to make assessment by comparing observed and predicted probabilities of model. In this test, Chi-square value of 4.8347 is recorded with p-value of 0.7751 such that $p$-value recorded is more than 0.05 . The conclusion is therefore that, there is no evidence of difference between observed and predicted chance of occurrence of selfmedication at $\alpha=0.05$ level of significance.

\section{Conclusion}

The objective of this study was to model self medication risk factors. The following are observed about the proposed multivariate logistic regression model, first, the female gender have higher chance of practicing self medication as compared to male gender, while unmarried persons have higher chances of self medication than widowed, separated, divorced or married persons. Secondly, when there is an increase in age of patient when all other variables are at reference level, there is higher chance of individual practicing self-medication. Thirdly, when there is an increase in income of patient when all other variables are at reference level, there is higher chance of individual practicing self-medication. Finally, as an individual achieves higher level of education there is higher chance of practicing self-medication.

In this study, it is also observed that the major selfmedication risk factors include but not limited to age, income, gender and education having recorded $\mathrm{p}$-values that were less than 0.05 and therefore would be considered in estimating self-medication prevalence. The multivariate logistic model would be considered key component in guiding policy makers and medical practitioners in making self-medication safe practice in society in order to avoid exposure to dangers of resistance to drugs, strain of limited facilities, seeking medical assistance from limited medical practitioners and preparing proposal for support from donors or national government.

\section{Recommendations}

(i) Attention should be given to female in providing them with necessary knowledge and awareness on self medication as results indicate that they have higher prevalence as compared to male in population.

(ii) The ministry of health should have laws, regulations and policies that guide self-medication treatments as the practice has not been regulated. The lower income earners may be exposed to buying cheap or second generation drugs that may not be appropriate for illness while low literacy persons require medical advice on use of drugs.

(iii) Studies should be conducted to assess suitability of drugs commonly used for self medication on effectiveness and how such access can be controlled to avoid exposure to residents who can get the correct advice from authorized sources such as medical care givers who have the necessary knowledge on prescriptions.

(iv) The policy makers should regularly review and classify medicinal products on basis of safety, efficiency, and monitor implementation of laws that govern the use and dispensation of medical products.

\section{References}

[1] Nuha, M. A. Agabna, A. Osman Awatif and A. Alsaddig Rand, (2014). Self-medication. Sudan_Journal of Rational Use of Medicine 6: 4-6.

[2] Hermandez-Juyol, M. and J. R. Job-Quesada, (2002). Dentistry and self-medication: A current challange. Medicina Oral 7(5):344-7.

[3] Darshan, Bennadi, (2014). Self-medication: A current challenge. Jounal of Basic and Clinical Pharmacy. 5(1): 19-23.

[4] Jessica, Flanigan. (2012). Three arguments against prescription requirements. Journal of Medical Ethics.

[5] Pankaj, Jain, et al. (2012). Statistical Study on Self Medication Pattern in Haryana, India. Indo Global Journal of Pharmaceutical Sciences: 2(1): 21-35.

[6] Vidyavati, S. D., et al. (2016). Self Medication Reasons, Risks and Benefits. International Journal of Healthcare and Biomedical Research 4:21-24.

[7] Kiyingi, K. S. and J. A. K. Lauwo, (1993). Drugs in Home: Danger and Waste. World Health Forum: 14: 381-384.

[8] Vidyavati, S. D., et al. (2016). Self Medication Reasons, Risks and Benefits. International Journal of Healthcare and Biomedical Research 4:21-24

[9] Hughes, C., J. McElnary and G. Fleming (2001).. Benefits and Risks of Self Medication. Drug Saf 24:1027-37.

[10] Ferney-Voltaire, Franc (2006). World Self-Medication Industry. Responsible Self-Care and Self-Medication. A Worldwide Review of Consumer Surveys.

[11] El-Nimr, N. A., et al. (2015). Self-medication with drugs and complementary and alternative medicines in Alexandria, Egypt: prevalence, patterns and determinants. Eastern Mediterranean Health Journal 21(4).

[12] Remington, T. L., et al. (2006). Handbook of Nonprescription Drugs: An Interactive Approach to Self Care. Washington DC: American Pharmacists Association pp. 66-90. 
[13] Osemene, K. P. and A. Lamikanra. (2012). A study of the Prevalence of Self-medication Practice among University Students in Sourthwest Nigeria. Tropical Journal of Pharmaceutical Research 11(4): 683-689.
[14] Robert, V. Krejcie and W. Morgan Daryle, (1970). Determining Sample Size for Research Activities. Educational and Psychological Measurement, 30, 607-610. 